\title{
AVALIAÇÃO DA BIOSSOLUBILIZAÇÃO DE FOSFATO POR MICRO-ORGANISMOS SOLUBILIZADORES
}

\author{
H. R. R. DE AGUIAR ${ }^{1}$, G. F. ALVES ${ }^{1}$, V. L. CARDOSO ${ }^{1}$ e S. L. CARDOSO ${ }^{1}$ \\ ${ }^{1}$ Universidade Federal de Uberlândia, Faculdade de Engenharia Química \\ E-mail para contato: hericlesresende@gmail.com
}

\begin{abstract}
RESUMO - O fósforo (P) é um macroelemento essencial para manutenção da vida de animais e plantas. É encontrado na natureza na forma de numerosos minerais, tal como a apatita. A indústria de mineração realiza a extração e o beneficiamento das reservas fosfáticas. No processo industrial ocorrem perdas consideráveis deste elemento por meio de rejeitos industriais ou por lixiviação pela chuva. $\mathrm{O}$ fósforo arrastado pela chuva pode ocasionar a redução do oxigênio dos corpos d' água (eutrofização), necessário para manutenção da vida. Outro aspecto industrial relevante diz respeito à produção de fertilizantes que tradicionalmente utiliza ácidos inorgânicos fortes (ácido sulfúrico) para obtenção de formas mais solúveis de fosfato, gerando subprodutos impactantes ao meio ambiente. Dentro deste contexto, o presente trabalho propôs uma possível alternativa para o tratamento de rejeitos e ao processamento químico tradicional, rota sulfúrica, pela utilização de fungos Aspergillus niger, excretores de ácidos orgânicos (menos impactantes) que por mecanismos de quelação e reações de troca iônica, aumentam acentuadamente a concentração de fósforo em solução.
\end{abstract}

\section{INTRODUÇÃO}

O fósforo não é encontrado nativo na natureza, sendo extraído de diferentes minerais. Em termos mundiais, mais de $99 \%$ dos fertilizantes fosfatados são produzidos a partir de reservas de rochas fosfáticas e apenas uma quantidade muito pequena é fornecida na forma de escórias básicas, um subproduto da indústria do aço. Além disso, atualmente, cerca de $85 \%$ da produção mundial de $\mathrm{P}$ vem de depósitos sedimentares de minas de superfícies e $15 \%$ de depósitos magmáticos (YAMADA; ABDALLA, 2004).

A indústria de mineração, com objetivo de atender a procura deste mineral, realiza a extração, beneficiamento e comercialização das reservas fosfáticas. No processo industrial de concentração do fosfato ocorrem perdas consideráveis deste elemento por meio de rejeitos industriais ou por lixiviação pela chuva. No aspecto técnico e econômico é necessária a recuperação deste mineral. Na questão ambiental, o fósforo proveniente de rejeitos ou por lixiviação é arrastado aos corpos d' água, acumulando-se nos leitos de rios, lagos e etc.

Diante disso, a presente pesquisa teve como objetivo geral propor um complemento ao processamento químico tradicional, uma alternativa para recuperação de rejeitos e 
minimização de perdas, e uma provável forma de beneficiamento de reservas de baixo teor (bases de reservas), que é a solubilização do fósforo proveniente de rocha fosfática pelo emprego de fungos $A$. niger através de processo fermentativo em estado líquido, e selecionar dentre os isolados fúngicos aqueles com maior potencial de solubilização.

\section{MATERIAIS E MÉTODOS}

\subsection{Rocha Fosfática}

A rocha fosfática utilizada no trabalho foi o concentrado fosfático ultrafino (fluorapatita), com teor de 35,7\% de $\mathrm{P}_{2} \mathrm{O}_{5}$, fornecido pelo Complexo de Mineração de Tapira (Vale/Fosfértil), localizado na região do Alto Paranaíba, Estado de Minas gerais.

\subsection{Fungo de Trabalho}

O fungo Aspergillus niger foi o escolhido para o trabalho. O mesmo foi fornecido pelo laboratório de Micologia e Proteção de Plantas do Instituto de Ciências Agrárias - ICIAG, da Universidade Federal de Uberlândia- UFU. O A. niger foi encontrado em sementes de soja coletadas em fazendas do município de Uberlândia-MG em tempo e locais variados.

Isolamento e repicagem: O fungo foi isolado das sementes de soja para obtenção das culturas puras. As repicagens foram realizadas para manutenção dos isolados. O isolamento consistiu na transferência da semente infectada para placas contendo meio BDA, formado por uma mistura de extrato de batata $(500 \mathrm{~mL})$, dextrose $(20 \mathrm{~g})$, ágar $(17-20 \mathrm{~g})$ e água destilada $(1000 \mathrm{~mL})$. Em seguida, as placas foram incubadas em câmara úmida a $\pm 25^{\circ} \mathrm{C}$ por período de 1 a 3 dias com a finalidade de se estimular a esporulação.

Finalizada a etapa do isolamento seguiu-se para a repicagem, onde colônias de esporos foram transferidas para placas com meio BDA. Em seguida, as placas foram incubadas por período de 5 a 7 dias a $25^{\circ} \mathrm{C}$. Esta primeira repicagem foi realizada com a finalidade de se desenvolver o fungo e observar possíveis contaminações provenientes do meio com sementes. Após isso, foram realizadas novas repicagens, 12 isolados puros foram obtidos, armazenados em tubos de ensaio e identificados aleatoriamente com números de 1 a 12.

Armazenamento e preservação: Os tubos de ensaio contendo os isolados foram armazenados em refrigerador a $\pm 4{ }^{\circ} \mathrm{C}$. Para garantir a viabilidade das culturas foram realizadas repicagens periódicas de 6 a 6 meses.

\subsection{Análise Qualitativa}

Após as etapas de isolamento e preservação, iniciou-se o processo de seleção dos isolados fúngicos, de acordo com a capacidade de solubilização do fosfato insolúvel. Inicialmente os 12 isolados de $A$. niger foram submetidos à avaliação qualitativa, com o propósito de identificar quais fungos possuíam tal capacidade. Para isto, foi empregado o meio sintético-seletivo (PIKOVSKAYA, 1948), mostrado na Tabela 1, para crescimento dos micro-organismos. 
Tabela 1 - Meio sintético-seletivo sólido

\begin{tabular}{ll}
\hline \multicolumn{1}{c}{ Componente } & Quantidade $(\mathrm{g} / \mathrm{L})$ \\
\hline Dextrose (= D-glicose) & 10,00 \\
Ágar & 15,00 \\
Extrato de Levedura & 0,50 \\
Fosfato tricálcico & 5,00 \\
Sulfato de Magnésio & 0,10 \\
Sulfato de amônio & 0,50 \\
Sulfato ferroso & 0,0001 \\
Sulfato de manganês & 0,0001 \\
Cloreto de potássio & 0,20 \\
\hline
\end{tabular}

Primeiramente os isolados foram repicados em placas contendo meio BDA e mantidos a $25{ }^{\circ} \mathrm{C}$ por 5 dias para crescimento. Em seguida, foi retirado um disco do meio de cultura de $0,5 \mathrm{~cm}$ de diâmetro contendo filamentos do fungo, por meio de um furador cilíndrico esterilizado previamente por flambagem. Discos dos 12 isolados foram inoculados em placas contendo meio seletivo. Em seguida, as placas foram incubadas a $25{ }^{\circ} \mathrm{C}$ por $48 \mathrm{~h}$. Após este período foi realizada a leitura para observação dos testes positivos, caracterizados pela presença de uma zona translúcida (halo) em torno da colônia fúngica.

\subsection{Análise Quantitativa}

Para realização da análise quantitativa foi preparado o meio seletivo modificado líquido (SUDHAKARA REDDY et al., 2002), em que o fosfato tricálcico foi substituído pelo concentrado fosfático ultrafino (fluorapatita) a $\pm 2 \%$, mostrado na Tabela 2.

Tabela 2 - Meio seletivo modificado

\begin{tabular}{ll}
\hline \multicolumn{1}{c}{ Componente } & Quantidade $(\mathrm{g} / \mathrm{L})$ \\
\hline Dextrose (= D-glicose) & 10,00 \\
Extrato de Levedura & 0,50 \\
Rocha fosfática & 24,00 \\
Sulfato de Magnésio & 0,10 \\
Sulfato de amônio & 0,50 \\
Sulfato ferroso & 0,0001 \\
Sulfato de manganês & 0,0001 \\
Cloreto de potássio & 0,20 \\
\hline
\end{tabular}


Nesse ensaio os isolados fúngicos marcados pelos testes positivos na avaliação qualitativa foram submetidos à classificação quantitativa, com a finalidade de se identificar entre os isolados aqueles com maior capacidade de solubilização do fosfato de rocha em meio líquido.

Porções de $70 \mathrm{~mL}$ do meio modificado foram distribuídas em Erlenmeyers de $125 \mathrm{~mL}$. Em seguida, foram inoculadas suspensões aquosas de $10^{6}$ esporos dos 12 isolados (em triplicata) por $\mathrm{mL}$ de meio modificado (SAMPAIO et al., 2003). Após isso, foi avaliada a solubilização da rocha fosfática para o tratamento sem agitação mecânica (a $30^{\circ} \mathrm{C}$ ) e com agitação mecânica (agitação a $120 \mathrm{rpm}$ e $30^{\circ} \mathrm{C}$ ) por 12 dias.

\subsection{Determinação de Fósforo Solúvel}

A determinação do fósforo solúvel em solução seguiu o procedimento descrito em APHA - AWWA - WEF (1998). Dessa maneira, o fósforo solúvel foi quantificado nos extratos líquidos (meio líquido) após os ensaios e determinado diretamente após a filtração da amostra com auxílio de papel de filtro para filtragem rápida.

Após o procedimento anterior, o ortofosfato liberado foi determinado pelo método colorimétrico do fosfato vanadomolibdato: Uma solução de ortofosfato reage com o molibdato de amônio e com vanádio para formação do ácido vanadomolibidatofosfórico, amarelo. A intensidade da cor amarela é proporcional à concentração do fósforo. A faixa de trabalho do método é de 1 a $10 \mathrm{mg} / \mathrm{L} \mathrm{(ppm)} \mathrm{de} \mathrm{fósforo} \mathrm{em} \mathrm{comprimento} \mathrm{de} \mathrm{onda} \mathrm{de} 420 \mathrm{~nm}$.

\subsection{Determinação de pH}

$\mathrm{O}$ pH foi determinado pelo procedimento descrito em APHA - AWWA - WEF (1998). Assim, a leitura do $\mathrm{pH}$ das amostras foi realizada pelo método potenciométrico, utilizando phmetro, introduzindo o eletrodo diretamente nos extratos líquidos ao final dos ensaios.

\section{RESULTADOS E DISCUSSÃO}

\subsection{Análise Qualitativa}

$\mathrm{Na}$ avaliação qualitativa os 12 isolados apresentaram capacidade de solubilização de fosfato insolúvel, verificada pela presença de um halo translúcido ao redor da colônia fúngica, o que era esperado visto que todos os isolados tratavam-se de $A$. niger. Deste modo, todos foram selecionados para a próxima etapa.

\subsection{Análise Quantitativa}

$\mathrm{Na}$ análise quantitativa calculou-se a média, para cada isolado, dos valores de fósforo solúvel e de $\mathrm{pH}$ obtidos nos ensaios em triplicata e a partir disso realizou-se o teste estatístico dos valores médios de fósforo solúvel pelo procedimento descrito em (Scott; Knott, 1974). As Tabelas 3 e 4 apresentam o teste aglomerativo (Teste de Scott - Knott) para o sistema sem agitação e com agitação, respectivamente. 
Tabela 3 - Teste de Scott - Knott dos resultados para o tratamento sem agitação

\begin{tabular}{cccccccc}
\hline Isolado & $\mathrm{P}(\mathrm{mg} / \mathrm{L})$ & $\mathrm{pH}$ & $\begin{array}{c}\text { Scott- } \\
\text { Knott }\end{array}$ & Isolado & $\mathrm{P}(\mathrm{mg} / \mathrm{L})$ & $\mathrm{pH}$ & $\begin{array}{c}\text { Scott- } \\
\text { Knott }\end{array}$ \\
\hline 3 & 253,3 & 3,43 & $\mathrm{a} 1$ & 12 & 372,2 & 3,24 & $\mathrm{a} 4$ \\
4 & 322,3 & 3,56 & $\mathrm{a} 2$ & 5 & 372,8 & 3,25 & $\mathrm{a} 4$ \\
8 & 343,4 & 3,33 & $\mathrm{a} 3$ & 2 & 383,5 & 2,91 & $\mathrm{a} 5$ \\
9 & 350,1 & 3,18 & $\mathrm{a} 3$ & 7 & 386,8 & 3,31 & $\mathrm{a} 5$ \\
11 & 360,2 & 3,19 & $\mathrm{a} 4$ & 1 & 387,3 & 3,04 & $\mathrm{a} 5$ \\
10 & 369,0 & 2,98 & $\mathrm{a} 4$ & 6 & 387,4 & 3,06 & $\mathrm{a} 5$ \\
\hline
\end{tabular}

Tabela 4 - Teste de Scott - Knott dos resultados para o tratamento com agitação

\begin{tabular}{cccccccc}
\hline Isolado & $\mathrm{P}(\mathrm{mg} / \mathrm{L})$ & $\mathrm{pH}$ & $\begin{array}{c}\text { Scott- } \\
\text { Knott }\end{array}$ & Isolado & $\mathrm{P}(\mathrm{mg} / \mathrm{L})$ & $\mathrm{pH}$ & $\begin{array}{c}\text { Scott- } \\
\text { Knott }\end{array}$ \\
\hline 2 & 316,3 & 3,24 & $\mathrm{a} 1$ & 1 & 394,5 & 2,99 & $\mathrm{a} 3$ \\
4 & 327,1 & 3,14 & $\mathrm{a} 1$ & 12 & 401,5 & 2,98 & $\mathrm{a} 4$ \\
8 & 341,7 & 3,12 & $\mathrm{a} 2$ & 6 & 405,4 & 2,97 & $\mathrm{a} 4$ \\
5 & 376,9 & 3,15 & $\mathrm{a} 3$ & 3 & 409,2 & 2,94 & $\mathrm{a} 4$ \\
10 & 387,9 & 3,03 & $\mathrm{a} 3$ & 7 & 440,4 & 2,86 & $\mathrm{a} 5$ \\
11 & 387,9 & 3,01 & $\mathrm{a} 3$ & 9 & 460,3 & 3,06 & $\mathrm{a} 6$ \\
\hline
\end{tabular}

O teste de Scott - Knott, para o sistema sem agitação, apresentou 5 grupos de isolados estatisticamente diferentes. Os isolados do grupo a5 apresentaram melhores resultados. Embora os membros deste grupo sejam estatisticamente iguais, os fungos 6 , 1 e 7 demonstraram, nesta ordem, as melhores médias.

Já para o sistema com agitação, o teste de Scott - Knott apresentou 6 grupos de isolados estatisticamente diferentes. O fungo do grupo a6, Isolado 9, foi o que apresentou melhor desempenho, seguido pelo Isolado 7 do grupo a5.

Como o Isolado 7 apresentou bom desempenho nos tratamentos, sem e com agitação, e como o Isolado 9 foi o melhor fungo no tratamento com agitação, estes foram os dois isolados selecionados com o maior potencial solubilizador. 


\section{CONCLUSÃO}

Observando os resultados, não foi verificada nenhuma tendência na comparação dos valores de $\mathrm{P}$ solúvel e $\mathrm{pH}$ entre as espécies de $A$. niger, ou seja, entre os isolados. Entretanto, conforme relatos na literatura, esperava-se que um menor $\mathrm{pH}$ refletisse em um aumento de $\mathrm{P}$ solúvel. Uma provável explicação para este fato está relacionada ao ácido orgânico produzido, que não foi possível ser determinado pela metodologia utilizada. Porém, para uma mesma espécie de $A$. niger verificou-se que um menor $\mathrm{pH}$ refletiu em um maior valor de solubilização.

O A. niger apresentou um bom rendimento em solubilização do fosfato de rocha, demonstrando ser um agente promissor. Porém, entre espécies diferentes constata-se bastante heterogeneidade de solubilização. $\mathrm{O}$ tratamento com agitação mecânica apresentou melhores resultados que o tratamento sem agitação, isto por que a agitação auxilia na mistura de constituintes do meio de cultura, reduzindo ou eliminando gradientes de concentração e de temperatura, tornando, assim, o meio mais homogêneo. A agitação também promove uma melhor transferência da massa ar-líquido e mantém os sólidos e a biomassa em suspensão.

\section{REFERÊNCIAS}

APHA - AWWA - WEF. Standard Methods for the Examination of Water and Wastewater, 20th ed. Washington, D. C.: Americam Public Health Association., 1998. - part 4000 Inorganic nonmetallic constituents, $4500-\mathrm{H} \mathrm{pH}$ value.

APHA - AWWA - WEF. Standard Methods for the Examination of Water and Wastewater, 20th ed. Washington, D. C.: Americam Public Health Association., 1998. - part 4000 Inorganic nonmetallic constituents, 4500-P Phosphorus.

PIKOVSKAYA, R.I. Mobilization of phosphorus in soil in connection with vital activity of some microbial species. Microbiologiya., v.17, 362-370, 1948.

SAMPAIO, R.M.; Alegre, R. M.; MARCOS, S.K.; BARROTI, G.; UBEDA, B. T. Estudo da Solubilidade de Fosfato de Rocha Tipo Tapira por Fungos do Gênero Aspergillus. In: XIV Simpósio Brasileiro de Fermentações - SINAFERM, 2003, Florianopólis. Anais do. XIV Simpósio Brasileiro de Fermentações - SINAFERM, 2003.

SCOTT, A.J.; KNOTT, M.A. Cluster analysis method for grouping means in the analysis of variance. Biometrics, Washington, v. 30, p. 507-512, Sept. 1974.

SUDHAKARA REDDY, M.; KUMAR, S.; BABITA, K., REDDY, M.S. Biosolubilization of poorly soluble rock phosphates by Aspergillus tubingensis and Aspergillus niger. Bioresource Technology., v. 84, p. 187-189, 2002.

YAMADA, T.; ABDALLA, S.R.S. Fósforo na agricultura brasileira. Associação brasileira para pesquisa da potassa e do fosfato. Piracicaba. 2004. 